\title{
Study of Inhibition and Adsorption Properties of Mild Steel Corrosion by Expired Pharmaceutical Gentamicin Drug in Hydrochloric acid media
}

\author{
A. SRINIVASULU ${ }^{1 *}$, P.K.KASTHURI ${ }^{2}$ \\ ${ }^{1}$ Research and Development Centre, Bharathiar University, Coimbatore, Tamil Nadu, India. \\ ${ }^{2}$ Department of Chemistry, L.R.G.Government Arts College for Women, Tirupur, Tamil Nadu, India. \\ *Correspondence should be addressed to A.Srinivasulu,achus.aslu@gmail.com
} http://dx.doi.org/10.13005/ojc/330559

(Received: April 27, 2017; Accepted: June 06, 2017)

\begin{abstract}
This experiment avoids pollution and recycles of the drugs and also promotes economically benefited inhibitor. In this experiment expired Gentamicin drug was under studied for testing its inhibitive effect on mild steel in $1 \mathrm{M} \mathrm{HCl}$ acid medium with the weight loss and electrochemical techniques. The Various parameters were calculated such as corrosion rate, inhibition efficiency and surface coverage. The weight loss method shows that the inhibition efficiency increases when inhibitor concentration, immersion period and temperature increases. Obtained results in electrochemical Impedance and weight loss studies are very much excellent agreement with each other. Thermodynamic parameter like free energy value was negative, that shows spontaneous adsorption of inhibitor on the surface of the mild steel. The adsorption nature of the inhibitor on the surface of mild steel was under conformity with Langmuir adsorption isotherm. The mild steel surface morphology, with and without inhibitor was studied by using scanning electron microscopy
\end{abstract}

Keywords: Mild steel,acidic medium, economically benefitted corrosion inhibitor, expired-drug, electrochemical Impedance and weight loss methods, the mild steel surface morphology

\section{INTRODUCTION}

Simple accessibility, minimal effort of mellow steel has numerous industrial applications. It is broadly utilized as a part of different ventures like sugar, cowhide, sustenance, petrochemical, paper and material businesses. In most mechanical procedures, the acidic arrangements are regularly utilized for the pickling,acid cleaning, de-scaling of acids etc. The decreasing corrosion rate of metals spares the current assets and thusly creates conservative advantages amid the mechanical applications. The lifetime of types of gear can be expanded and viable corrosion restraint will diminish the disintegration of harmful metals from the parts into nature ${ }^{1-3}$. Hydrochloric acid is most the most corrosive with most of the common metals and alloys, difficult of this acid to handle from corrosion and materials of constructions, due to its industrial applications the corrosion inhibitors are became an answer for corrosion attack witch lead to metal damage and also replacement of the metal. Many reviews on consumption inhibitors tell that a large portion of the inhibitors are organic with $\mathrm{N}, \mathrm{O}$ and $\mathrm{S}$ atoms or with polar groups of $\mathrm{N}$-hetero cyclic 
compounds. They have fundamental properties with high electron thickness, making them the response focuses ${ }^{4-10}$. These block the dynamic corrosion locations by adsorption on the metallic surface and the majority of them are exceedingly dangerous to the people and also the earth. Thus replacement by these eco-friendly inhibitors is necessary. The use of pharmaceutical compounds which are contains hetero atoms in their structure, high solubility and high molecular weight offers interesting possibilities for corrosion inhibition ${ }^{11-20}$. Few drugs like azosulpha and antimalarial have been accounted for that they are great corrosion inhibitors on mild steel ${ }^{21-23}$. In thisreview Gentamicindrug (Eye/Ear Drops) that has been expired is chosen for the corrosion inhibitionon the mild steel in $1 \mathrm{M}$ hydrochloric acid medium by utilizing weight loss, electrochemical spectroscopy strategies. Gentamicinis a non-toxic pharmaceutical medication used to prevent or treat a wide variety of bacterial infections. It belongs to a class of drugs known as amino glycoside antibiotics, it contain $\mathrm{N}$ - atom having high electron density to block the active sites of corrosion. The inhibitor is available in the brand name of 'Gentamicin' fabricated in India by CIPLA LTD it goes about as an anticorrosive agent for mild steel in hydrochloric acid medium.

\section{Materials}

Mild steel strips that are mechanically cut into segments (strips) of dimensions $5 \mathrm{~cm} \mathrm{x} 1 \mathrm{~cm}$ $x 0.2 \mathrm{~cm}$, with a hole $(2 \mathrm{~mm})$ which has a uniform diameter length at one of its end for hooking. The composition of strip is as follows: $0.256 \% \mathrm{Mn}$, $0.034 \% \mathrm{C}, 0.004 \% \mathrm{P}, 0.023 \% \mathrm{Si}$ and the remainder Fe. For studies in electrochemistry, these specimens of the same composition were made by fixing the mild steel of size $1 \mathrm{~cm}^{2}$ to a mild steel rod with a diameter $1 \mathrm{~mm}$ utilizing araldite. Every piece was polished with various grades of emery paper

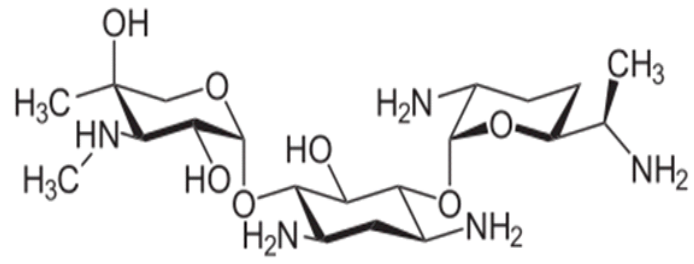

\section{Gentamicin}

and was degreased with acetone and was washed with some distilled water, dried and was stored in the desiccators. Weight of these specimens (strips) was given utilizing electronicbalance. Analar grade $\mathrm{HCL}$ acid and double time distilled water were utilized to make all the solutions. ExpiredGentamicin (Eye/Ear Drops)drug obtained from medical shop and used for this study without any further purification.

\section{RESULTS AND DISCUSSION}

\section{Weight loss method}

Initial weights ofthe pretreated example's are noted triplicate was inundated in the $100 \mathrm{ml}$ $(1 \mathrm{M} \mathrm{HCl})$ solution in nearnessandnonappearance of the inhibitors at various concentrations $(0.1,0.2$, $0.3,0.4,0.5,0.6,0.7,0.8,0.9$, and $1.0 \%$ ) for the period of $0.5,2,4,6,8$ and 24 hourswith the help of glass hooks after the experiment period the final weights were also noted and also studiedimpact of temperature on mild steel corrosionat fivedistinct temperatures ranging from $303 \mathrm{~K}$ to $343 \mathrm{~K}$. From this the inhibition efficiency (IE \%), rate of corrosion (mils Penetration per year), surface coverage $(\theta)$ were estimated by utilizing the following formulae.

$$
\operatorname{IE}(\%)=\frac{\mathrm{W}_{\mathrm{U}}-\mathrm{W}_{\mathrm{I}}}{\mathrm{W}_{\mathrm{U}}} \times 100
$$

Where, $W_{1}$ and $W_{u}$ are weight losses in acids with and without inhibitors respectively.

$$
\text { Corrosion rate }(\mathrm{mmpy})=\frac{87.6 \mathrm{x} \text { weight loss }(\mathrm{mg})}{\text { density } \left.(\mathrm{gm} / \mathrm{cc}) \times \text { area }\left(\mathrm{cm}^{2}\right) \times \text { time (hours }\right)}
$$

Corrosion parameters obtained from this method are given in Tables $1 \& 2$. It uncovers that, the inhibition efficiency incremented with the increase in temperature,concentration and immersion period of inhibitor asit is shown in the Figs 1 \& 2. The maximum inhibition efficiency $92.36 \%$ was noticed in 6 hours immersion period at room temperature $(303 \mathrm{~K})$ with concentration of $0.9 \%$. This outcome shows that the inhibitor could act as effective corrosion inhibitor for mild steel in $1 \mathrm{M} \mathrm{HCl}$ medium.

\section{Potentiodynamic Polarization method}

Electrochemical analyzer was used for Potentiodynamic polarization measurements. These estimations were made to assess the corrosion potential, corrosion current and Tafel slopes. A conventional three 
Table.1: Influence of concentration of Expired Gentamicin inhibitor on the corrosion of $1 \mathrm{M} \mathrm{HCl}$ at room temperature $(303 \mathrm{~K})$ with different time periods

\begin{tabular}{|c|c|c|c|c|c|c|c|c|c|c|c|c|}
\hline $\begin{array}{l}\text { Time } \\
\text { Inhibit. } \\
\text { or } \\
\text { Concen } \\
\text { (\%V/V) } \\
\end{array}$ & $\begin{array}{c}{ }^{1 / 2} \text { hours } \\
\text { CR } \\
\text { (mpy) } \\
\text { tration } \\
\end{array}$ & $\begin{array}{c}\text { IE } \\
(\%)\end{array}$ & $\begin{array}{c}2 \text { hours } \\
\text { CR } \\
\text { (mpy) }\end{array}$ & $\begin{array}{l}\text { IE } \\
\text { (\%) }\end{array}$ & $\begin{array}{l}4 \text { hours } \\
\text { CR } \\
\text { (mpy) }\end{array}$ & $\begin{array}{c}\text { IE } \\
(\%)\end{array}$ & $\begin{array}{c}6 \text { hours } \\
\text { CR } \\
\text { (mpy) }\end{array}$ & $\begin{array}{c}\text { IE } \\
\text { (\%) }\end{array}$ & $\begin{array}{c}8 \text { hours } \\
\text { CR } \\
\text { (mpy) }\end{array}$ & $\begin{array}{l}\text { IE } \\
\text { (\%) }\end{array}$ & $\begin{array}{c}24 \text { hours } \\
\text { CR } \\
\text { (mpy) }\end{array}$ & $\begin{array}{c}\text { IE } \\
(\%)\end{array}$ \\
\hline Blank & 514.52 & & 590.34 & & 633.18 & & 47.62 & & 699.58 & & 14.34 & \\
\hline 1 & 4 & 40.22 & 21 & 44.3 & & 49.28 & & 55.23 & & 52.36 & & 43.26 \\
\hline .2 & 408.64 & 47.65 & 395.64 & 53.26 & 3 & 57.23 & 386.98 & 60.21 & 2.82 & 58.65 & 67 & 49.68 \\
\hline .3 & 321.76 & 55.36 & 314.06 & 60.25 & 506.16 & 64.65 & 293.19 & 67.64 & 308.19 & 65.23 & 3.68 & 58.31 \\
\hline .4 & 249.08 & 63.21 & 238.18 & 66.21 & | 229.06 & 69.36 & 221.98 & 72.63 & D.68 & 70.26 & 279.98 & 62.35 \\
\hline 0.5 & 187.23 & 65.23 & 180.64 & 68.65 & 517 & 72.25 & 166.82 & 75.34 & 184.96 & 73.65 & 223.14 & 67.32 \\
\hline 0.6 & 146.72 & 67.54 & 138.21 & 71.26 & 13 & 74.65 & 123.04 & 78.26 & 142.08 & 76.31 & 180.86 & 69.11 \\
\hline 0.7 & 138.66 & 69.28 & 127.82 & 74.63 & 3124.67 & 78.56 & 102.98 & 83.69 & 126.82 & 79.98 & 139.68 & 73.01 \\
\hline 0.8 & 124.28 & 73.02 & 121.36 & 77.65 & 115.29 & 83.99 & 98.89 & 88.69 & 111.21 & 85.02 & 125.68 & 76.99 \\
\hline 0.9 & 119.66 & 76.65 & 112.99 & 80.36 & 106.28 & 86.23 & 95.29 & 92.36 & 107.08 & 88.55 & 116.69 & 80.64 \\
\hline 1.0 & 126.78 & 74.36 & 118.87 & 78.21 & 116.72 & 83.26 & 110.88 & 87.66 & 116.66 & 85.06 & 146.95 & 74.66 \\
\hline
\end{tabular}

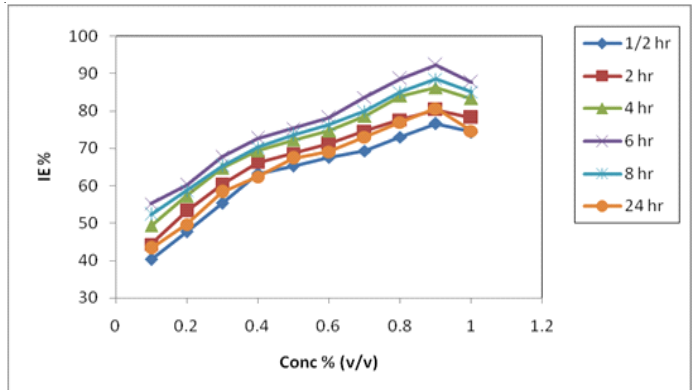

Fig.1. Gentamicin inhibitor Inhibition efficiency with various concentrations and time periods at the room temperature $(303 \mathrm{~K})$

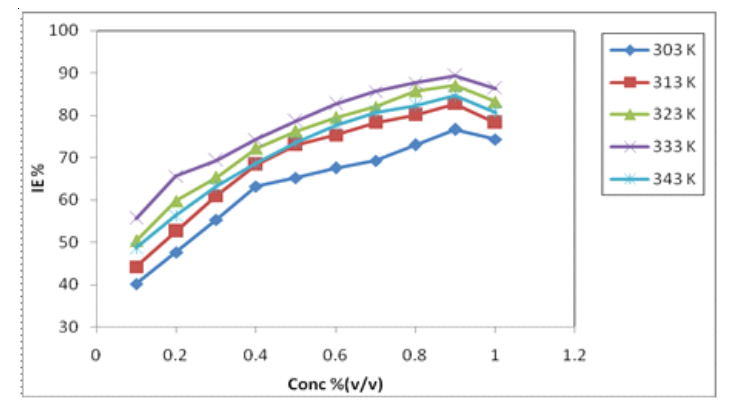

Fig. 2. Gentamicin inhibitor Inhibition efficiency with various concentrations and temperatures

Table. 2: Effect of temperature on the corrosion of mild steel in the presence of difference concentration of Expired Gentamicin inhibitor in 1M HCL

\begin{tabular}{|c|c|c|c|c|c|c|c|c|c|c|}
\hline $\begin{array}{l}\text { Temperature } \\
\text { Inhibit } \\
\text { or } \\
\text { concentratio } \\
(\% \mathrm{~V} / \mathrm{V})\end{array}$ & $\begin{array}{l}\text { 303K3 } \\
\text { CR } \\
\text { (mpy) }\end{array}$ & $\begin{array}{l}\text { IE } \\
(\%)\end{array}$ & $\begin{array}{c}13 \mathrm{~K} \\
\mathrm{CR} \\
\text { (mpy) }\end{array}$ & $\begin{array}{l}\text { IE } \\
(\%)\end{array}$ & $\begin{array}{c}323 \mathrm{~K} \\
\text { CR } \\
\text { (mpy) }\end{array}$ & $\begin{array}{l}\text { IE } \\
(\%)\end{array}$ & $\begin{array}{c}333 \mathrm{~K} \\
\text { CR } \\
(\mathrm{mpy})\end{array}$ & $\begin{array}{l}\text { IE } \\
\text { (\%) }\end{array}$ & $\begin{array}{c}\text { CR } \\
\text { (mpy) }\end{array}$ & $\begin{array}{c}343 \mathrm{~K} \\
\mathrm{IE} \\
(\%)\end{array}$ \\
\hline Blank & 514.52 & & 1539.18 & & 3519.25 & & 8109.48 & & 16527.78 & \\
\hline 0.1 & 472.69 & 40.22 & 1006.36 & 44.28 & 2432.69 & 50.36 & 5257.26 & 55.65 & 11063.23 & 48.65 \\
\hline 0.2 & 408.64 & 47.65 & 821.63 & 52.64 & 1802.69 & 59.82 & 3806.23 & 65.63 & .21 & 56.32 \\
\hline 0.3 & 321.76 & 55.36 & 563.21 & 60.98 & 1698.31 & 65.32 & 2722.61 & 69.36 & 5423.65 & 63.21 \\
\hline 0.4 & 249.08 & 63.21 & 390.23 & 68.36 & 1230.65 & 72.16 & 1960.23 & 74.32 & 3994.25 & 68.65 \\
\hline 0.5 & 187.23 & 65.23 & 269.32 & 72.98 & 893.22 & 76.21 & 1426.33 & 78.61 & 2904.66 & 73.63 \\
\hline 0.6 & 146.72 & 67.54 & 188.78 & 75.36 & 647.23 & 79.45 & 999.69 & 82.65 & 1725.36 & 77.65 \\
\hline 0.7 & 138.66 & 69.28 & 169.08 & 78.22 & 499.29 & 82.01 & 785.25 & 85.65 & 1529.99 & 80.65 \\
\hline 0.8 & 124.28 & 73.02 & 162.55 & 80.11 & 466.21 & 85.75 & 726.32 & 87.65 & 1389.45 & 82.31 \\
\hline 0.9 & 119.66 & 76.65 & 158.36 & 82.65 & 438.62 & 87.06 & 665.32 & 89.31 & 1198.32 & 84.65 \\
\hline 1.0 & 126.78 & 74.36 & 166.32 & 78.23 & 528.95 & 83.22 & 869.66 & 86.32 & 1456.01 & 80.65 \\
\hline
\end{tabular}


electrode cell assembly which contains working electrode as the mild steel specimen with area $1 \mathrm{~cm}^{2}$ which is exposed and rest covered with araldite, the rectangular $\mathrm{Pt}$ foil was used as counter electrode and theSCE as reference electrodes. To get the steady state open circuit potential for each test, ten to thirty of minutes time interval was given.
Polarization measurements were given out from the cathode with potential of $-450 \mathrm{mV}$ (vs. SCE) to an anode with potential of $-250 \mathrm{mV}$ (vs. SCE)at a sweep rate of $10 \mathrm{mV}$ per second. From the polarization curves corrosion potential, Tafel slopes and corrosion rates were calculated. The inhibitor efficiency was given by utilizing the following formulas.

Table. 3: Electrochemical polarization (Tafel) parameters for the corrosion of mild steel in $1 \mathrm{M} \mathrm{HCL}$ without and with various concentrations of inhibitor at room(303 K) temperature

\begin{tabular}{lccccccc}
\hline $\begin{array}{l}\text { conc. } \\
(\%)\end{array}$ & $-E_{\text {corr }}(\mathbf{m V})$ & $\begin{array}{c}\mathbf{I}_{\text {corr }} \\
\left(\mathbf{m A} / \mathbf{c m}^{2}\right)\end{array}$ & $\begin{array}{c}\mathrm{I}_{\text {corr }} \\
\mathbf{I E}(\%)\end{array}$ & $\begin{array}{c}\mathbf{b}_{\mathrm{a}} \\
(\mathbf{m V / d e c})\end{array}$ & $\begin{array}{c}\mathbf{b}_{\mathrm{c}} \\
(\mathbf{m V} / \mathbf{d e c})\end{array}$ & $\left.\mathbf{R}_{\mathrm{p}} \mathbf{\Omega c m}^{2}\right)$ & $\begin{array}{c}\mathbf{R}_{\mathrm{p}} \\
\mathbf{I E}(\%)\end{array}$ \\
\hline Blank & 346.8 & 0.996 & - & 70.0 & 114 & 18.92 & - \\
0.4 & 306.0 & 0.355 & 64.16 & 77.0 & 107 & 54.86 & 65.51 \\
0.7 & 304.5 & 0.329 & 66.90 & 70.0 & 110 & 56.27 & 66.38 \\
0.9 & 305.1 & 0.249 & 75.06 & 68.0 & 109 & 73.15 & 74.13 \\
\hline
\end{tabular}

Inhibition efficiency $=\quad \frac{\mathrm{I}_{\text {corr }}-\mathrm{I}_{\text {corr (i) }}}{\mathrm{I}_{\text {corr }}} \times 100$

Inhibition efficiency $=\frac{R_{p(i)}-R_{p}}{R_{p(i)}} \times 100$

Where, $\mathrm{I}_{\text {corr }}$ and $\mathrm{I}_{\text {corr(i) }}$ are the corrosion current in absence and presence of the inhibitor, similarly $R_{p}$ and $R_{p(i)}$ arethe polarization resistance in the absence and presence of the inhibitor.

Polarization studies observed that when concentration of inhibitor increased from $0.4 \%$ to $0.9 \%$ the $\mathrm{I}_{\text {corr }}$ values decreased $0.996 \mathrm{~mA} / \mathrm{cm}^{2}$ to $0.249 \mathrm{~mA} / \mathrm{cm}^{2}$ with inhibition value increase from $64.16 \%$ to $75.06 \%$ and also $\left(R_{p}\right)$ values increased from 18.92 Ù $\mathrm{cm}^{2}$ to $73.15 \mathrm{U} \mathrm{cm}^{2}$ with increase of inhibition efficiency from $65.51 \%$ to $74.13 \%$. Tafel polarization behaviors of the mild steel $1 \mathrm{M} \mathrm{HCL}$ shows in the Fig 3 . From the graph we can observe that the inhibitor behaves like mixed type [24-28]. In the Table 3. All the calculated data of Polarization studies was given.

\section{Electrochemical Impedance methods}

In the estimations of electrochemical impendence, cell same as utilized for potentiodynamic polarization. An AC potential 50 $\mathrm{mV}$ was super forced on the consistent open circuit potential. The genuine part ( $\left.Z^{\prime}\right)$ and the fanciful part
(Z") were measured at different frequencies in the scope of $10 \mathrm{kHz}$ to $10 \mathrm{MHz}$. The genuine and imaginary parts of the impendence were plotted in Nyquist plots. From the plots of Z' versus Z," the charge transfer resistance $\left(R_{c t}\right)$ quantities were acquired. The estimation of $\left(R_{t}+R_{s}\right)$ compares to the point where the plot cuts $z^{\prime}$ and at a higher frequency the distinction amongst $\mathrm{Rt}$ and Rs gives the charge exchange resistance $R_{c t}$ values. The dowble layer capacitance $C_{d l}$ quantities were acquired from the condition

$1 \mathrm{~A}=\mathrm{BLANK}, 1 \mathrm{~B}=0.4 \%, 1 \mathrm{C}=0.7 \%, 1 \mathrm{D}=0.9 \%$

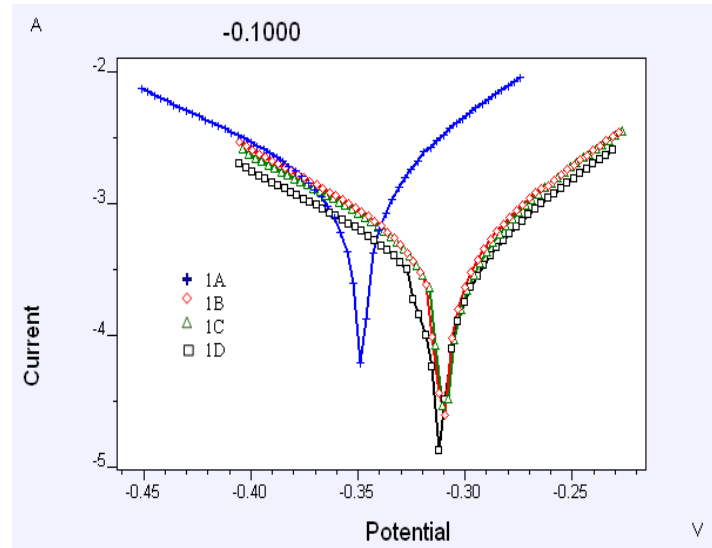

Fig. 3. Potentiodynamic polarization technique diagram for mild steel in $1 \mathrm{M} \mathrm{HCl}$ in the absence and presence of different concentrations of the inhibitor 


$$
\mathrm{C}_{\mathrm{d} 1}=\frac{1}{2 \pi \mathrm{f}_{\max } \mathrm{R}_{\mathrm{ct}}}
$$

Where, $\mathrm{C}_{\mathrm{dl}}$ means double layer capacitance

$R_{c t}$ means charge transfer resistance

$\mathrm{f}_{\max }$ means frequency at $\mathrm{Z}$ " value maximum.

The inhibition efficiencies were got from $R_{p}$ and $R_{c t}$ quantities as follows

$$
\text { Inhibition efficiency }=\frac{R_{P_{(i)}}-R_{p}}{R_{p(i)}} \times 100
$$

Where, $\mathrm{R}_{\mathrm{ct}}$ and $\mathrm{R}_{\mathrm{ct}(\mathrm{i})}$ are charge transfer resistance in the absenceand presence of the inhibitor Nyquist plots shows in the Fig. 4 for the measurements of the genuine part ( $\left.Z^{\prime}\right)$ and imaginary one (Z"). We can conclude the corrosion is mostly controlled by the process of charge transfer from semi-circle curves of the impedance. In Table.4, parameters for impedance of mild steel in $1 \mathrm{M} \mathrm{HCL}$ in the presence and absence of the inhibitor are shown. The values of $R_{c t}$ had increased

Table. 4: Electrochemical impedance parameters for the corrosion of mild steel in

$1 \mathrm{M} \mathrm{HCl}$ without and with various concentrations of inhibitor at room(303 K) temperature

\begin{tabular}{lccc}
\hline Conc.(\%) & $\mathrm{R}_{\mathrm{ct}}\left(\Omega \mathrm{cm}^{2}\right)$ & $\mathrm{C}_{\mathrm{dl}} \mu \mathrm{F} / \mathrm{cm}^{2}$ & $\mathrm{IE}(\%)$ \\
\hline blank & 3.43 & 438 & - \\
0.4 & 9.21 & 132 & 62.76 \\
0.7 & 12.95 & 164 & 73.51 \\
0.9 & 15.91 & 106 & 78.44 \\
\hline
\end{tabular}

$1 \mathrm{~A}=\mathrm{BLANK}, 1 \mathrm{~B}=0.4 \%, 1 \mathrm{C}=0.7 \%, 1 \mathrm{D}=0.9 \%$

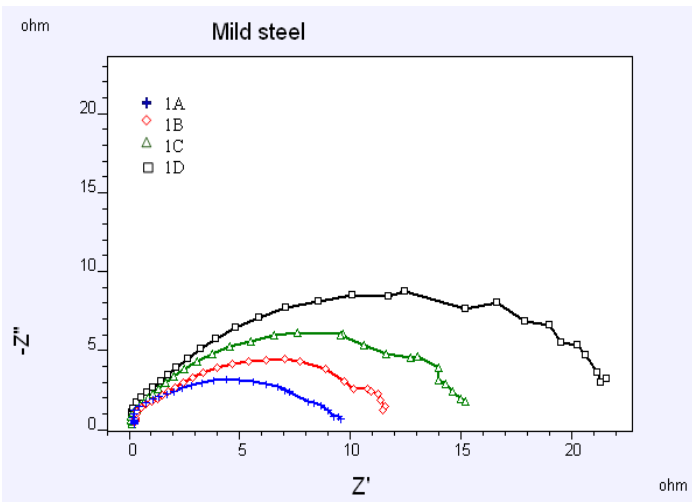

Fig. 4.Impedance technique for mild steel diagram in $1 \mathrm{M} \mathrm{HCl}$ in the absence and presence of different concentrations of the inhibitor from 3.43 Ù $\mathrm{cm}^{2}$ to $15.91 \mathrm{Ùcm}^{2}$ and simultaneously the values of $\mathrm{C}_{\mathrm{dl}}$ had decreased $438 \mathrm{iF} / \mathrm{Cm}^{2}$ to 88 $\mathrm{i} F / \mathrm{Cm}^{2}$ with the increase in inhibitor concentrations.

\section{Thermodynamic Consideration}

From the following Arrhenius equation the activation energy with different concentrations at various temperatures was calculated.

$$
\log \frac{\rho_{2}}{\rho_{1}}=\frac{E_{a}}{2.303 \times R}\left[\frac{1}{T_{1}}-\frac{1}{T_{2}}\right]
$$

Where, $\tilde{n}_{1}$ corrosion rate at $T_{1}$ and $\tilde{n}_{2}$ at $T 2$ temperature. ' $R$ ' is a real gas constant.

The change in free energy at different temperatures comparison with room temperature for various concentration of inhibitor was calculated using the following equation

$$
\begin{aligned}
& \Delta \mathrm{G}_{\text {ads }}=-2.303 \times 8.314 \times \mathrm{T} \times \mathrm{Log}(\mathrm{K} \times 55.5) \\
& \mathrm{K}=\frac{\theta}{(1-\theta) \mathrm{C}}
\end{aligned}
$$

Where, Surface coverage (è), Concentration (C), Temperature ( $\mathrm{T})$ \& Equilibrium constant $(\mathrm{K})$. The change in enthalpy of adsorption ("H) and change in entropy of adsorption ("S) can be calculated by using the following equations.

${ }^{\Delta} \mathrm{H}=\mathrm{E}_{\mathrm{a}}-\mathrm{RT}$

$$
\Delta \mathrm{S}=\frac{\Delta \mathrm{H}-\Delta \mathrm{G}}{\mathrm{T}}
$$

The values for mild steel in $1 \mathrm{M} \mathrm{HCl}$ acid with and without the inhibitor of the activation energy (Ea), free energy ("Gads), the entropy ("S) and the enthalpy ("H) are calculated and are shown in Table 5. Value of activation energy (Ea) of blank is 73.83 $\mathrm{kJ} \mathrm{mol}^{-1}$ and $51.66 \mathrm{~kJ} \mathrm{~mol}^{-1}$ for $0.9 \%$ inhibitor concentration, it's now clear that the addition of the inhibitor leads to decrease in the obvious activation energy (Ea) with some value lesser than the value of uninhibited solution which is trailed by the dull decline with the incrementation in the concentration of the inhibitor which points out the action upon mild steel in the $1 \mathrm{M} \mathrm{HCl}$ acid takes place through via the chemical adsorption. Negative value of free energy of the adsorption ("Gads) points out adsorption which is spontaneous. +ve values of 
enthalpy recommend that high temperatures will favor the complexation process and same in fantastic agreement with the incrementing stability with the temperature. The negative estimations of ÄSact indicated a greater order which is generated during the activation process. This can be accomplished by the creation of initiated complex and it shows the affiliation or fixation with the resulting loss in the degrees of the freedom of amework(system) in this procedure. This also supports suppositionof the chemical adsorption. Figure 5 illustrates the Arrhenius plot for the mild steel dissolution in the $1 \mathrm{M} \mathrm{HCl}$ acid without and with the inhibitor at various temperatures.

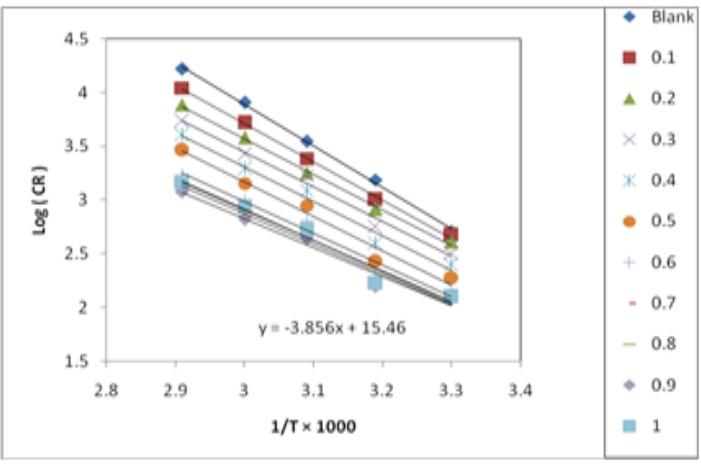

Fig. 5. Arrhenius plot for mild steel dissolution in $1 \mathrm{M} \mathrm{HCl}$ from $303 \mathrm{~K}$ to $343 \mathrm{~K}$ temperature with and without inhibitor

\section{Adsorption Consideration}

Corrosion Inhibition is identified with the adsorption of inhibitor mol on metal surface. Surface coverage $(\theta)=I E / 100$. In order to find out the adsorption isotherm for present review, a plot $\mathrm{C} / \theta$ and $\mathrm{C}$ ought to be straight. This is demonstrative the adsorption takes after Langmuir adsorption isotherm. These isotherms give the best fit with the correlation co efficient almost near to (0.9989) unity. In Fig. 6 shows a straight line showing that Langmuir adsorption isotherm. Organic molecules contain polar atoms which are adsorbed on metal surface and interact with mutual attraction or repulsion. Because this plot is straight, the angles are never solidarity, Langmuir adsorption isotherm shown as:

$$
\mathrm{C} / \theta=1 / \mathrm{k}+\mathrm{C}
$$

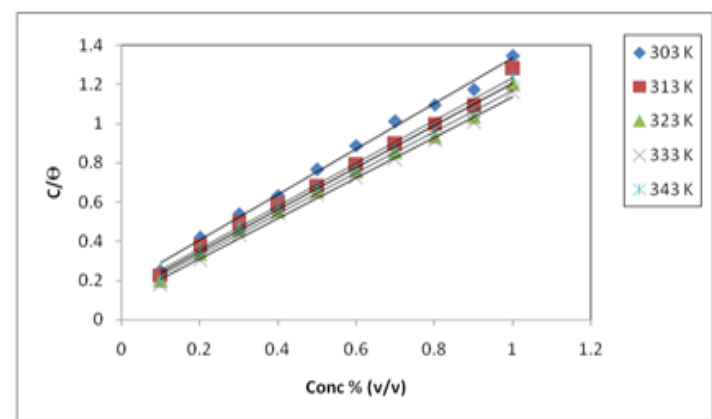

Fig. 6. Langmuir isotherm plot on mild steel surface in $1 \mathrm{M} \mathrm{HCl}$ solution for the adsorption of inhibitor

Table. 5: Thermodynamic data for mild steel corrosion in $1 \mathrm{M} \mathrm{HCl}$ in the presence and absence of Expired Gentamicin inhibitor in $1 \mathrm{M} \mathrm{HCl}$ for the period of $1 / 2$ hour.

\begin{tabular}{|c|c|c|c|c|c|c|c|c|c|c|c|c|c|}
\hline $\begin{array}{l}\text { inhibit. } \\
\text { or } \\
\text { Conc. } \\
\text { (\%V/V) }\end{array}$ & $\begin{array}{c}\mathrm{Ea} \\
(\mathrm{KJ} / \mathrm{mo}\end{array}$ & & & & & & $\begin{array}{l}-\Delta \mathrm{G} \\
\mathrm{J} / \mathrm{mol})\end{array}$ & & & & & $\begin{array}{c}-\Delta \mathrm{S} \\
(\mathrm{KJ} / \mathrm{mol})\end{array}$ & $\begin{array}{c}\Delta \mathrm{H} \\
(\mathrm{KJ} / \mathrm{mol})\end{array}$ \\
\hline $\begin{array}{l}\text { temp } \\
\text { Blank }\end{array}$ & 73.83 & $\theta$ & $303 K$ & $\theta$ & $313 \mathrm{~K}$ & $\theta$ & $323 \mathrm{~K}$ & $\theta$ & $333 \mathrm{~K}$ & $\theta$ & $343 K$ & $303 \mathrm{~K}$ & $\begin{array}{l}303 K \\
71.31\end{array}$ \\
\hline 0.1 & 67.97 & 0.402 & 14.92 & 0.442 & 15.34 & 0.503 & 15.95 & 0.556 & 16.49 & 0.486 & 15.78 & 0.265 & 65.45 \\
\hline 0.2 & 63.36 & 0.476 & 13.93 & 0.526 & 14.44 & 0.598 & 15.17 & 0.656 & 15.80 & 0.563 & 14.81 & 0.246 & 60.84 \\
\hline 0.3 & 61.92 & 0.553 & 13.69 & 0.609 & 14.27 & 0.653 & 14.74 & 0.693 & 15.21 & 0.632 & 14.51 & 0.241 & 59.4 \\
\hline 0.4 & 61.33 & 0.632 & 13.79 & 0.683 & 14.36 & 0.721 & 14.82 & 0.743 & 15.10 & 0.686 & 14.40 & 0.239 & 58.81 \\
\hline 0.5 & 61.16 & 0.652 & 13.45 & 0.729 & 14.36 & 0.762 & 14.79 & 0.786 & 15.14 & 0.736 & 14.45 & 0.237 & 58.64 \\
\hline 0.6 & 56.45 & 0.675 & 13.25 & 0.753 & 14.22 & 0.794 & 14.81 & 0.826 & 15.33 & 0.776 & 14.54 & 0.221 & 53.93 \\
\hline 0.7 & 54.09 & 0.692 & 13.06 & 0.782 & 14.23 & 0.820 & 14.84 & 0.856 & 15.51 & 0.806 & 14.61 & 0.213 & 51.57 \\
\hline 0.8 & 54.03 & 0.730 & 13.19 & 0.801 & 14.19 & 0.857 & 15.20 & 0.876 & 15.61 & 0.823 & 14.55 & 0.213 & 51.51 \\
\hline 0.9 & 51.66 & 0.766 & 13.38 & 0.826 & 14.31 & 0.870 & 15.18 & 0.893 & 15.73 & 0.846 & 14.68 & 0.206 & 49.14 \\
\hline 1.0 & 55.91 & 0.743 & 12.80 & 0.782 & 13.34 & 0.832 & 14.15 & 0.863 & 14.76 & 0.806 & 13.71 & 0.218 & 53.39 \\
\hline
\end{tabular}


Table. 6: Inhibition efficiency competition of inhibitor for mild steel in $1 \mathrm{M} \mathrm{HCl}$ from weight loss, polarization and impedance techniques for the period of $1 / 2$ hour studies

\begin{tabular}{lllll}
\hline \multicolumn{4}{c}{ Inhibition efficiency (\%) } \\
\hline \multicolumn{4}{c}{ Polarization } \\
\hline Conc.(\%) Weight loss & $\mathbf{I}_{\text {corr }}$ & $\mathbf{R}_{\mathrm{p}}$ & Impedance \\
\hline & & & & \\
$0.4 \%$ & 63.21 & 64.16 & 65.51 & 62.76 \\
$0.7 \%$ & 69.28 & 66.90 & 66.38 & 73.51 \\
$0.9 \%$ & 76.65 & 75.06 & 74.13 & 78.44 \\
\hline
\end{tabular}

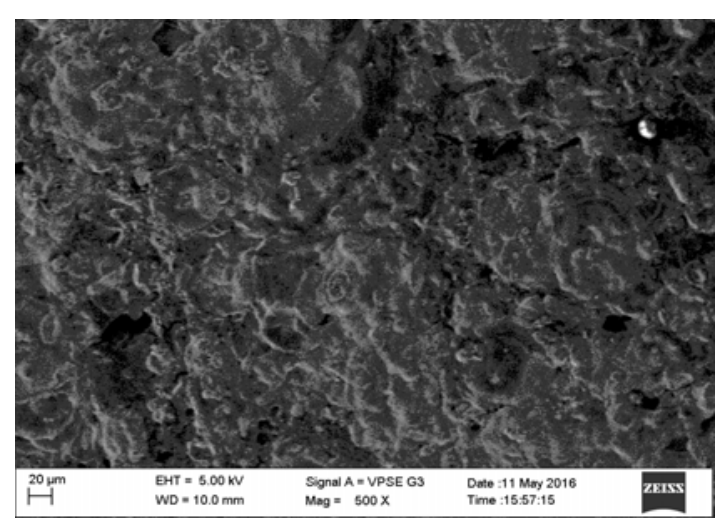

Fig. 7. The SEM photo of mild steel when immersed in $1 \mathrm{M} \mathrm{HCl}$ without inhibitor

\section{Morphology examination}

The photos of mild steel in acid medium containing without and with the inhibitor are shown in Fig. $7 \&$. It is watched that the assault of mild steel within the existence of inhibitor in $1 \mathrm{M} \mathrm{HCl}$ is less compared to the nonappearance of inhibitor, because of the presence of adsorbed layer of the inhibitor which blocks corrosion rate of metal evidently. This is ascribed to the contribution of the compound of the interaction of the inhibitor with active sites on surface of metal, thus results in enhanced surface coverage of the metal so that there is decrease in contact amongst aggressive medium and the metal.

\section{CONCLUSION}

The expired Gentamicin(Eye/Ear drops) pharmaceutical drug acts as excellent, efficient and economically benefitted inhibitor on the mild steel corrosion in the $1 \mathrm{M} \mathrm{HCl}$ acid medium. The efficiency of the inhibitor is found to increase with period of immersion, temperatures and concentration. The Inhibitor with concentration $(0.9 \%)$ showed

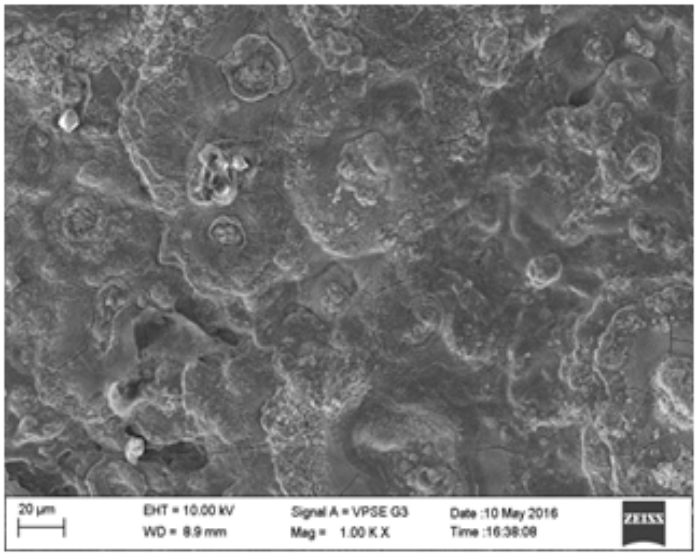

Fig. 8. The SEM photo of mild steel when immersed in $1 \mathrm{M} \mathrm{HCl}$ containing $0.9 \%$ concentration of inhibitor.

maximum efficiency $(92.36 \%)$ in $6 \mathrm{~h}$ immersion period at room temperature (303K) and found sufficient for pickling. The chemical adsorption mechanism of the inhibition process was conformation with the data obtained; Langmuir adsorptions were best fitted into the obtained results. Thermodynamic parameters like activation energy (Ea) values also conformed to a chemical adsorption mechanism. Free energy (Gads) of absorptionvalues are negative which pointed out spontaneous adsorption of the inhibitor on the metal surface. The positive values of Enthalpy are proposing high temperature favors inhibition efficiency. The semi circle curves of impedance points that corrosion is mainly controlled by phenomena of charge transfer. High performance of the inhibitive effect on the surface of mild steel has confirmed by SEM morphology of protective film. Obtained results in electrochemical and weight loss studies are very much excellent agreement with each other. This experiment promotes ecofriendly and economically benefitted inhibitor and also avoids pollution and recycles the drugs. Inhibition efficiency competition of inhibitor for mild steel in $1 \mathrm{M} \mathrm{HCl}$ for three difference methods is given in the Table 6.

\section{ACKNOWLEDGEMENT}

This research was supported by research and development centre, bharathiar university, coimbator, tamilnadu, india. We thank our colleagues from department of chemistry, I. R.g.government arts college, tirupur. P.k.kasthuri 
medam Provided insight and expertise that greatly assisted the Research, Conclusions of this paper.

I thank A. Parameswar, $r$ \& $d$ center for assistance with particular technique, methodology] for comments that greatly improved the manuscript. We would also like to show our gratitude to my colleagues for sharing their pearls of wisdom with us during the course of this research.

\section{REFERENCE}

1. Aejitha .S, Kasthuri .P. K and Geethamani , Corrosion Studies With Antigonon Leptopus In 1 $\mathrm{M} \mathrm{HCl}$, Int. J. Chem. Sci:: 2015,13(1), 38-52

2. Amine .M.A and Ibrahim .M.M, corrosion and corrosion control of mild steel in concentrated H2SO4 solutions by a newly synthesized glycine derivative, Corros. Sci. 2011, 53, 873-885.

3. Ishtiaque .A, Rajendra .P and Quraishi .A.M, Inhibition of mild steel corrosion in acid solution by Pheniramine drug: Experimental and theoretical study, Corros. Sci. 2010, 52, 3033-3041

4. Bentiss .F, Bouanis .M M., Marwari .B, Traisnel .M, and Lagrenée .M.M, Effect of iodide ions on corrosion inhibition of mild steel by $3,5-$ bis(4-methylthiophenyl)-4H-1,2,4-triazole in sulfuric acid solution, J. Appl. Electrochem, 2002, 32, 671-678.

5. Fouda .S, Elewady .G.Y, Shalabi .K and Habouba .S, Tobacco Plant Extracts as Save corrosion Inhibitor for Carbon Steel in Hydrochloric Acid Solutions, IJAR, 2014, 2(3), 817-832

6. Onuegbu .T.U, Umoh .E.T and Onuigbo .U.A, Eupatorium Odoratus As Eco-Friendly Green Corrosion Inhibitor Of Mild Steel In Sulphuric Acid, International Journal Of Scientific \& Technology Research, 2013,2(2), 4-8

7. Quraishi .M.A, Dileep Kumar Yadav and Ishtiaque Ahamad, Green Approach to Corrosion Inhibition by Black Pepper Extract in Hydrochloric Acid Solution, The Open Corrosion Journal , 2009, 2, 56-60

8. Leelavathi .S and Rajalakshmi .R, Dodonaea viscosa (L.) Leaves extract as acid Corrosion inhibitor for mild Steel - A Green approach, J. Mater. Environ. Sci. 2013, 4(5), 625-638

9. Priyaa .S.V and Saratha .R, Inhibition of mild steel corrosion in $0.5 \mathrm{H} 2 \mathrm{SO} 4$ with leaves extract, Elixir Corrosion, 2011 , 37 , 3617-3622

10. Abdallah .M and El-Naggar .M.M, Cu+2 cation $+3,5$-dimethyl pyrazole mixture as a corrosion inhibitor for carbon steel in sulfuric acid solution, Mater. Chem. Phys., 2001, 71, 291-298.

11. Aejitha .S, Kasthuri .P.K, Inhibition Action of Mild Steel Corrosion in $\mathrm{HCl}$ Acid Medium by Extract of Digera Muricata, International Journal of Science and Research, 2014,3(9), 607- 611.

12. Selvamani .P, Latha .S and Dhivya .P.S, AntiInflammatory Activity of Extracts of Commiphora Species and Its Polyherbal Formulation, International Journal of Phytopharmacology. 2013, 4(5), 288- 292

13. Sudarshana Deepa .V, Suresh Kumar .P, Latha .S, Selvamani .P and Srinivasan .S,Antioxidant Studies on the Ethanolic Extract of Commiphora Spp, African Journal of biotechnology, 2009, 8 (8), 1630-1636

14. GeethaKodali and Ganapaty Seru, Antihyperlipidemic Activity of Commiphora Caudata Leaves In Atherogenic Diet Induced Rats, International Journal of Biological \& Pharmaceutical Research. 2013, 4(4), 250-255.

15. Adeyemi .O.O and Olubomehin .O.O , Investigation of Anthocleistadjalonensis Stem Bark Extract as Corrosion Inhibitor for Aluminum, The Pacific Journal of Science and Technology, 2010,11(2), 455-462.

16. Ehteram A. Noor, Temperature Effects on the Corrosion Inhibition of Mild Steel in Acidic Solutions by Aqueous Extract of Fenugreek Leaves, Int. J. Electrochem. Sci., 2007, 2, $996-1017$

17. Anbarasi .K and Vasudha .V.G , Corrosion Inhibition Potential of Cucurbita Maxima Plant Extract on Mild Steel in Acid Media, Chemical Science Review and Letters, 2014, 3(9), 45-51

18. Ladha .D.G, Naik .U.J and Shah .N.K, Investigation of Cumin (CuminumCyminum) extract as an ecofriendly green corrosion inhibitor for pure Aluminium in Acid medium, J. Mater. Environ. Sci. 2013, 4 (5), 701-708. 
19. Gunavathy .N and Murugavel .S.C, Study On The Effect Of Musa AcuminataFlower Extract On The Corrosion Inhibition Of Mild Steel In $1 \mathrm{~N}$ H2SO4, Int. J. Chem. Sc.: 2013, 11(1), 475-486

20. Rajalakshmi .R, Subhashini .S, Leelavathi .S and Geethajali .R, Study Of The Inhibitive Action Of Bakery Waste For Corrosion Of Mild Steel In Acid Medium ,J. Nep. Chem Soc., 2010, 25, 29-36 .

21. Vasudha .V.G and Shanmuga Priya .K, PolyalthiaLongifoliaas a Corrosion Inhibitor for Mild Steel in $\mathrm{HCl}$ Solution, Research 1 2013, 3(1), 21-26

22. Priya .S.V and Saratha .R, Inhibition of mild steel corrosion in $0.5 \mathrm{H} 2 \mathrm{SO} 4$ with leaves extract, Elixir Corrosion, 2011, 37, 3617-3622

23. Aouine.Y, Sfaira .M, EbnTouhami .M, Alami .A, Hammouti .B, Elbakri .M, El Hallaoui .A and Touir .R, Temperature and Time Investigations on the Adsorption Behavior of Isoindoline, Tetrazole and Isoindoline-Tetrazole on Corrosion of Mild Steel in Acidic Medium, Int. J. Electrochem. Sci., 2012, 7, $5400-5419$

24. Sheeja .V.N and Subhashini .S, 2014, PavettalndicaBark as Corrosion Inhibitor in Mild Steel Corrosion in $\mathrm{HCl}$ and $\mathrm{H} 2 \mathrm{SO} 4$ Medium: Adsorption and Thermodynamic Study, Chemical Science Transactions, 2014, 3(1), 129-140

25. SrinivasaReddy .C, Ammani.K, RoseMary.T,
Nikhil Rajesh.D, Aravind.G, and ChandraBala Sekaran, Phytochemical and GC-MS analysis of Commiphoracaudata(Wt. \&Arn.) Eng. Bark, Indian Journal of Advances in Plant Research, 2014, 1(5), 24-29.

26. Martinez .S and Stern .I, Thermodynamic characterization of metal dissolution and inhibitor adsorption processes in the low carbon steel/ mimosa tannin/sulfuric acid system, Appl. Surf. Sci., 2002, 199 (1), 83- 89.

27. KhuloodA.saleh, Khalil S. Khalil, Corrosion Inhibition Of Zinc In Hydrochloric Acid Solution Using Ampicillin, Iraqi Journal of Science, 2014, 55, 295-303.

28. Ambrish Singh and Eno E. Ebenso, Use of Glutamine as a New and Effective Corrosion Inhibitor for Mild Steel in $1 \mathrm{M} \mathrm{HCl}$ Solution,Int. J. Electrochem. Sci., 2013, 8, $12874-12883$

29. Khadom .A.A, Yaro .A.S, AlTaie .S and Kadum A.H, Electrochemical, Activations and Adsorption Studies for the Corrosion Inhibition of Low Carbon Steel in Acidic Media,PortugaliaeElectrochimica Acta , 2009, 27(6), 699-712.

30. Sharmila .A, AngelinPrema .A and Arockia Sahayaraj .P, Influence Of MurrayaKoenigii (Curry Leaves) Extract On The Corrosion Inhibition Of Carbon Steel In $\mathrm{HCl}$ Solution, Rasayan .J.Chem., 2010, 3(1), 74- 81. 